OPEN ACCESS

Edited by:

Zhongjun Jia,

Institute of Soil Science (CAS), China

Reviewed by:

Xiang Gao,

Japan International Research Center

for Agricultural Sciences (JIRCAS),

Japan

Yo-Jin Shiau,

National Taiwan University, Taiwan

*Correspondence:

Jun Yan

yanjun@iga.ac.cn

Specialty section:

This article was submitted to

Terrestrial Microbiology,

a section of the journal

Frontiers in Microbiology

Received: 18 November 2019

Accepted: 21 July 2020

Published: 18 August 2020

Citation:

Zhang Z, Han X, Yan J, Zou W, Wang E, Lu X and Chen X (2020) Keystone Microbiomes Revealed by 14 Years of Field Restoration of the Degraded Agricultural Soil Under

Distinct Vegetation Scenarios.

Front. Microbiol. 11:1915.

doi: 10.3389/fmicb.2020.01915

\section{Keystone Microbiomes Revealed by 14 Years of Field Restoration of the Degraded Agricultural Soil Under Distinct Vegetation Scenarios}

\author{
Zhiming Zhang ${ }^{1}$, Xiaozeng Han ${ }^{1}$, Jun Yan ${ }^{1 *}$, Wenxiu Zou ${ }^{1}$, Entao Wang ${ }^{2}$, Xinchun Lu' \\ and Xu Chen ${ }^{1}$ \\ ${ }^{1}$ National Observation Station of Hailun Agro-Ecology System, Key Laboratory of Mollisols Agroecology, Northeast Institute \\ of Geography and Agroecology, Chinese Academy of Sciences, Harbin, China, ${ }^{2}$ Departamento de Microbiología, Escuela \\ Nacional de Ciencias Biológicas, Instituto Politécnico Nacional, Mexico City, Mexico
}

Agricultural intensification accelerates the degradation of cropland, and restoration has been managed by changing its vegetation. However, the keystone microbiome that drives the decomposition of plant-associated organic matter in the restoration is poorly understood. In this study, we established a 14-year field restoration experiment on a degraded cropland with four treatments: (1) bare land soil without biomass input (BL), (2) maize cropland (CL) without fertilization and biomass input, (3) natural grassland $(G L)$, and (4) alfalfa cropland (AL) with biomass left in the fields. The activity of total soil microbiome was assessed by community-level physiological profiling (CLPP) with Biolog EcoPlates analysis, and keystone microbiome was identified as phylotypes showing statistically significant increase in the restored soils ( $G L$ and $A L$ ) relative to the degraded $\mathrm{BL}$ soil. The results showed that $\mathrm{GL}$ and $\mathrm{AL}$ treatments improved soil fertility as indicated by significant increase in soil organic carbon, total nitrogen, and available phosphorus when compared to $\mathrm{BL}$ treatment. The significant difference was not observed between $\mathrm{CL}$ and $\mathrm{BL}$ treatments except for $\mathrm{pH}$ and available phosphorus, indicating that the input and microbial decomposition of plant-associated organic matter were the key for restoration of soil fertility. Similar results were obtained for soil microbial activities of carbon utilization efficiency via CLPP analysis, and real-time quantitative polymerase chain reaction of $16 \mathrm{~S}$ rRNA genes further revealed significantly higher abundance of total soil microbial community in $\mathrm{GL}$ and $\mathrm{AL}$ soils than in $\mathrm{BL}$ and $\mathrm{CL}$. High-throughput sequencing of total $16 \mathrm{~S}$ rRNA genes revealed the Bacteroidetes as the only keystone taxa at phylum level, and 106 and 120 genera were keystone phylotypes. Compared with $B L$ and $C L$, the genera that increase significantly in $G L$ and $A L$ are called keystone genera of ecological restoration. The dominant keystone genera included Reyranella, Mesorhizobium, Devosia, Haliangium, Nocardioides, and Pseudonocardia. Significantly higher abundance of Bacillus genus in BL soil implied it might serve as an indicator of agricultural land degradation. Statistical analysis showed that soil organic carbon and $\mathrm{pH}$ were significantly correlated with the input of plant-associated organic matters and dynamic changes of keystone taxa. These results suggest that the vegetation of natural 
grass (GL) and alfalfa plant (AL) and subsequent decomposition of plant-associated materials could serve as effective strategies for restoration of the degraded cropland by stimulating the keystone microbiomes and improving their physiological metabolisms of carbon utilization efficiency.

Keywords: ecological restoration, microbial-community composition, metabolism of carbon sources, soil nutrient contents, black soil

\section{INTRODUCTION}

Soil degradation is of great concern in every agricultural region of the world because of its long-term negative effects on soil productivity (Bindraban et al., 2012; Gong et al., 2013). Conventional agriculture managements, such as intensive monoculture, tilling, and fertilization, can degrade soil and fragment habitats, which can in turn affect the health of agricultural ecosystems and threaten the survival of humans (Foley et al., 2005). Revegetation is a widely accepted restoration strategy, as the development of plant communities can improve soil physical structures, enhance accumulation of soil organic matter, and optimize the ecosystem services (Guo et al., 2018; Wang et al., 2019). Numerous studies have indeed been reported toward plant-mediated restoration of agricultural land in the United States (Alexander and Allan, 2007), Europe (Lamers et al., 2014), Brazil (Mendes et al., 2015), and China (Hou et al., 2019) through increased soil organic carbon (SOC) content and improved ecosystem function with increasing organic matter input and reducing disturbance ( $\mathrm{Li}$ et al., 2007; Hou et al., 2010). In the context of background of sustainable development, the ecological restoration of degrade area has gradually raised people's awareness and attracted extensive concerns across the world (Gong et al., 2013; Ilunga wa Ilunga et al., 2015).

The success of ecological restoration depends entirely on soil microbiomes that decompose plant-associated organic matters and improve soil physicochemical characteristics (Audino et al., 2014; Deng et al., 2020). Soil microorganisms are primary drivers of ecosystem processes in terms of nutrient cycling and energy transfer and significantly associated with regulating multiple ecosystem functions and enhancing ecosystem stability (Su et al., 2015). Soil microbial community structure and function are often considered to be sensitive to small variations in soil environment such as SOC and $\mathrm{pH}$. Meanwhile, vegetation, landuse conversion, crop management, tillage intensity (Donnison et al., 2000; Pankhurst et al., 2002), and cultivation history (Bossio et al., 2005; Yao et al., 2006; Lauber et al., 2008) can also modify soil bacterial communities. Vegetation restoration with ryegrass (Lolium perenne L.) was more conducive to altering the microbial community structure than red clover (Trifolium pratense L.). However, understanding the diversity and function of soil microbial communities has been severely hampered because of the technical limitations in past decades because

Abbreviations: AL, Alfalfa land; AP, Available phosphorus; AWCD, Average well-color development; BL, Bare land; CL, Cropland; CLPP, Community level physiological profiles; EN, Exchangeable nitrogen; GL, Grassland; OD, Optical density; OTUs, Operational taxonomic units; PCA, Principal Component Analysis; PCoA, Principal coordinate analysis; qPCR, Quantitative real-time PCR; RDA, Redundancy analysis; SOC, Soil organic carbon; TN, Total nitrogen. cultivation-dependent approaches can hardly represent what is naturally occurring under field conditions. The advent of high-throughput sequencing allows identification of keystone microbiomes in complex environments at unprecedented resolution in recent years. Guo et al. (2018) reported that natural revegetation of a semiarid habitat increased the microbial taxonomic diversity with plant diversity, and soil organic matter could explain most variations of microbial community structures. It has also been shown that the predominance of Acidobacteria was replaced by Proteobacteria after a 30-year land abandonment on the Loess Plateau (Zhang et al., 2016). However, contradictory observations have been reported, and it was often attributed to ecosystem-level heterogeneity. Meanwhile, the mere presence of functional genes does not necessitate metabolic activities of microbial communities in complex environments, although high-throughput sequencing can decipher taxonomic identities of total microbial communities at unprecedented level. Community-level physiological profiles (CLPPs) with Biolog EcoPlates can provide important insights into the functional diversity of soil microbial communities along distinct restoration scenarios (Rutgers et al., 2016). The microbial carbon metabolism represented by average well color development (AWCD) can be used to estimate the SOC mineralization. CLPPs are reproducible and sensitive to soil texture, soil type, tillage, land use, and vegetation restoration (Chou et al., 2016; Furtak et al., 2017). It has been shown that the increased bacterial diversity was likely associated with the reduced microbial carbohydrate catabolism under the biochar amendments (Chen et al., 2019). Grassland in the Netherlands and elsewhere in Europe tend to have higher functional diversity than do arable systems (Rutgers et al., 2016). Carbohydrates, amino acids, and carboxylic acids are more sensitive than other carbon sources as indicators of the health of black-soil grassland (Meng et al., 2008). However, to the best of our present understanding, there is no integrative study on both function (CLPP) and diversity (high-throughput sequencing) patterns of soil microbial communities in response to ecological restoration of degraded agricultural land.

Black soil, Udolls in the US Department of Agriculture (USDA) soil taxonomic system (Staff, 2014), is a typical soil characterized by high fertility and productivity, with native prairie in northeastern China representing $13.5 \%$ of the global area of black soil (IUSS Working Group WRB, 2007). In fact, this region is often considered as the most important agricultural land for crop production in China, particularly soybean and maize. The physicochemical properties of black soil, however, have changed drastically, especially SOC depletion, because agricultural land was reclaimed in the last hundred years. Numerous studies have shown significant deterioration of 
agricultural soils due to intensified anthropogenic interference, which poses great challenges for sustainable agriculture in China (Hao et al., 2017; You et al., 2019). Nonetheless, the microbial mechanisms underlying the restoration of agriculturally important lands are poorly understood. Therefore, four different treatments were established in 2003 on a degraded agricultural land for ecological restoration including (1) bare land (BL) control; (2) cropland (CL) control; (3) grassland (GL) for natural restoration; (4) alfalfa land (AL). A combination suite of techniques including classic functional approach (Biolog EcoPlates) and culture-independent molecular analysis [real-time quantitative polymerase chain reaction (PCR) and high-throughput sequencing] was then employed to decipher the keystone soil microbiome that are responsible for restoration of the degraded land under different planting regimes after a 14-year field management.

\section{MATERIALS AND METHODS}

\section{Site Description and Experiment Design}

This work was carried out in the Hailun National Field Observation and Research Station ( $\left.47^{\circ} 27^{\prime} \mathrm{N}, 126^{\circ} 55^{\prime} \mathrm{E}\right)$, Chinese Academy of Sciences, in Heilongjiang Province, China. This site has a typical continental monsoon climate. Mean annual rainfall is about $550 \mathrm{~mm}$, with greater than $65 \%$ occurring between June and August. Mean annual temperature is $2.2^{\circ} \mathrm{C}$, with mean monthly temperatures ranging from $-23.5^{\circ} \mathrm{C}$ in January to $21.0^{\circ} \mathrm{C}$ in July. The area has a frost-free period of approximately 120 days. The soil is classified in the USDA soil taxonomy as an Udoll (Staff, 2014) derived from loamy loess, with a clay content of approximately 30\% (Hao et al., 2017). The study site was a native prairie before crop cultivation about 200 years ago. No fertilizer was applied until cropping system was established 160 years ago. Chemical fertilizers (NPK) were used over 25 years before the setup of long-term experiments in 2003. Maize (Zea mays L.) as the major crop species is generally sown by row in May and harvested in October.

A long-term randomized-block field experiment was established in 2003, which consisted of three replicate plots of four treatments: (1) bare land (BL) control, the vegetation of wild grass was removed whenever emerged; (2) cropland (CL) control, maize ( $Z$. mays L.) was planted without fertilizer application, and all aboveground biomass was removed; (3) grassland (GL) for natural restoration and Poa annua L., Equisetum arvense L., Spodiopogon sibiricus Trin. as the dominant species, the naturally occurring grass was left in the field; (4) alfalfa land (AL), the alfalfa (Medicago sativa L.) was planted, and the biomass was returned to the field. Each plot was $21.0 \mathrm{~m}^{2}(4.2 \times 5 \mathrm{~m})$ and isolated by cement barriers. Supplementary Figure $S 1$ shows the change of the aboveground biomass of CL, BL, AL, and BL from 2004 to 2016 (Supplementary Figure S1).

\section{Sampling and Analysis}

Five soil samples $(0-20 \mathrm{~cm})$ were randomly collected in each plot using a soil core auger (inner diameter of $7 \mathrm{~cm}$ ) in July 2017 and then combined. After removing the visible plant debris manually, the samples were immediately transported to the laboratory for sieving through a $2-\mathrm{mm}$ mesh and then stored at $4^{\circ} \mathrm{C}$ for studying the metabolism of $\mathrm{C}$ sources and at $-80^{\circ} \mathrm{C}$ for subsequent molecular analysis. Subsamples were air-dried for analyzing $\mathrm{pH}$ and the SOC, total nitrogen (TN), exchangeable nitrogen (EN), and available phosphorus (AP) contents. $\mathrm{pH}$ was measured in a 2:1 water:soil suspension using a $\mathrm{pH}$ meter (Jackson, 1973). SOC and TN contents were determined using a VarioEL CHN elemental analyzer (Heraeus Ele-mentar VarioEL, Hanau, Germany). EN content was determined using alkaline diffusion (Page et al., 1982). AP content was determined as described by Olsen and Sommers (Olsen and Sommers, 1982).

\section{Community-Level Physiological Profiles}

CLPPs were assessed using Biolog EcoPlates (Biolog Inc., CA, United States) containing $31 \mathrm{C}$ substrates. Briefly, $5.0 \mathrm{~g}$ of soil was suspended in $45 \mathrm{~mL}$ of a sterile $0.85 \% \mathrm{NaCl}$ solution, shaken for $30 \mathrm{~min}$, and allowed to settle for $30 \mathrm{~min}$. A 10-fold serial dilution up to $10^{-3}$ was then prepared. Each plate well was inoculated with $150 \mu \mathrm{L}$ of the $10^{-3}$ dilution, and the plates were incubated in the dark at $25^{\circ} \mathrm{C}$. The plates were read at 590 and $750 \mathrm{~nm}$ every $24 \mathrm{~h}$ for $192 \mathrm{~h}$ (8 days).

The optical densities (ODs) in each well were determined by subtracting the $750 \mathrm{~nm}$ values from the $590 \mathrm{~nm}$ values after correcting for the readings in a control well at the corresponding wavelengths. Negative ODs and ODs $<0.06$ were set to zero (Classen et al., 2003). The use of six types of C sources was then statistically analyzed. The final values for each well after 8 days were used to calculate average well-color development (AWCD) (Garland and Mills, 1991):

$$
\mathrm{AWCD}_{590-750 \mathrm{~nm}}=\frac{\sum C_{590-750}}{31}
$$

where 31 is the number of $\mathrm{C}$ sources used in the EcoPlates.

\section{Soil DNA Extraction}

Microbial DNA was extracted from $0.5 \mathrm{~g}$ of fresh soil sample using an E.Z.N.A. ${ }^{\S}$ soil DNA Extraction Kit (Omega Biotek, Norcross, United States) following the manufacturer's instructions. The final DNA concentration and purity were determined using a NanoDrop 2000 UV-Vis spectrophotometer (Thermo Fisher Scientific, Wilmington, NC, United States), and the quality was checked by electrophoresis on an agarose gel (1\%, wt/vol).

\section{Real-Time Quantitative PCR}

The number of copies of the bacterial 16S rRNA gene in each sample was determined in triplicate using quantitative PCR (qPCR) in an ABI 7500 Real-Time PCR System (Applied Biosystems, Carlsbad, United States) with the 515F/907R primer set (5'-GTGCCAGCMGCCGCGGTAA-3' and 5'CCGTCAATTCMTTTRAGTTT-3', respectively). Each PCR reaction contained $16.5 \mu \mathrm{L}$ of $2 \times$ SYBR Green qPCR Master Mix, $0.8 \mu \mathrm{L}$ of $5 \mu \mathrm{M}$ forward and reverse primers (each), 2.0 $\mu \mathrm{L}$ of template DNA, and $\mathrm{ddH}_{2} \mathrm{O} 33.0 \mu \mathrm{L}$. The PCR reactions were carried out at $95^{\circ} \mathrm{C}$ for $5 \mathrm{~min}$, followed by 40 cycles of 
denaturation at $95^{\circ} \mathrm{C}$ for $30 \mathrm{~s}$, annealing at $50^{\circ} \mathrm{C}$ for $30 \mathrm{~s}$, and elongation at $72^{\circ} \mathrm{C}$ for $60 \mathrm{~s}$. Negative controls contained all reagents, but the DNA was replaced with $\mathrm{ddH}_{2} \mathrm{O}$. The threshold cycle $(\mathrm{Ct})$ was obtained and averaged from triplicate samples. The number of copies of the $16 \mathrm{~S}$ rRNA gene was calculated using a regression equation for converting $\mathrm{Ct}$ to the known number of copies in standard curves.

\section{Illumina MiSeq Sequencing}

The 16S rRNA genes were amplified using the 515F and 907R primers in a PCR thermocycler (GeneAmp 9700, ABI). The reactions were performed in triplicate in $20-\mu \mathrm{L}$ mixtures containing $4 \mu \mathrm{L}$ of $5 \times$ FastPfu Buffer, $2 \mu \mathrm{L}$ of $2.5 \mathrm{mM}$ dNTPs, $0.8 \mu \mathrm{L}$ of each primer $(5 \mu \mathrm{M}), 0.4 \mu \mathrm{L}$ of FastPfu Polymerase, $0.2 \mu \mathrm{L}$ of bovine serum albumin, $10 \mathrm{ng}$ of template DNA, and $\mathrm{ddH}_{2} \mathrm{O}$ for supplementing to the final volume. The reactions were conducted using the program: denaturation at $95^{\circ} \mathrm{C}$ for $3 \mathrm{~min}$, 27 cycles of denaturation at $95^{\circ} \mathrm{C}$ for $30 \mathrm{~s}$, annealing at $55^{\circ} \mathrm{C}$ for $30 \mathrm{~s}$, and elongation at $72^{\circ} \mathrm{C}$ for $45 \mathrm{~s}$, with a final extension at $72^{\circ} \mathrm{C}$ for $10 \mathrm{~min}$. PCR products were extracted from a $2 \%$ (wt/vol) agarose gel after electrophoresis, purified using an AxyPrep DNA Gel Extraction Kit (Axygen Biosciences, Union City, United States), and quantified using QuantiFluor ${ }^{\S}$-ST (Promega, United States) following the manufacturer's instructions. Purified amplicons were pooled in equimolar concentrations and pairedend sequenced $(2 \times 300)$ on an Illumina MiSeq platform (Illumina, San Diego, CA, United States) following standard protocols provided by Majorbio Bio-Pharm Technology Co. Ltd. (Shanghai, China). The raw reads were deposited in the NCBI Sequence Read Archive database (accession no. PRJNA588746).

Raw sequence data were demultiplexed, filtered for quality using Trimmomatic, and merged using FLASH with the criteria: (1) the reads were truncated at sites with average quality scores $<20$ over a 50 bp sliding window; (2) the primers were matched exactly, allowing mismatches of two nucleotides, and reads containing ambiguous bases were removed; and (3) sequences with overlaps $>10$ bp were merged based on their overlap sequence. Operational taxonomic units (OTUs) were clustered with a similarity cutoff of $97 \%$ using UPARSE (version7.1 ${ }^{1}$; Edgar, 2013), and chimeric sequences were identified and removed using UCHIME (Edgar et al., 2011). The clean reads were assigned to the OTUs using the Silva (SSU123) 16S rRNA database and the RDP classifier algorithm (Quast et al., 2013). The data were analyzed using the free online Majorbio I-Sanger Cloud Platform ${ }^{2}$. Keystone taxa are defined as the phylotypes whose relative abundance showed statistically significant increase in soils of CL (A), GL (B), and AL (C) when compared with control bare soil BL. Meanwhile, the phylotype showing significant decline in GL and AL soils could be considered as indicative taxa of soil degradation.

\section{Statistical Analysis}

Multiple comparisons of Duncan multiple range tests were used to identify significant changes in the number of copies of

${ }^{1}$ http://drive5.com/uparse/

${ }^{2} \mathrm{http} / / /$ www.i-sanger.com the $16 \mathrm{~S}$ rRNA gene and significant changes to groups at the phylum level $(P<0.05)$ (SPSS Inc., United States). A principal component analysis (PCA) conducted using the vegan (2.56) package was used to analyze the characteristics of $\mathrm{C}$-source metabolism at the community level. CL, GL, and AL were compared to BL at the genus level using STAMP (v2.1.4) $t$-tests to identify keystone taxa (genera) with significant changes in relative abundances $(P<0.05)$ (Parks et al., 2014). A principal coordinate analysis (PCoA) based on Jaccard and Bray-Curtis distances was performed at the OTU level for all samples. In order to examine the effects of ecological restoration on microbial community, analysis of similarities (ANOSIM) (Clarke and Ainsworth, 1993) was performed. Correlations among the treatments were estimated using the Bray-Curtis distances to cluster all samples. A redundancy analysis (RDA) was performed to estimate the correlations between the microbial communities and soil properties. Pearson correlation was used to determine the relationships between soil properties and microbial community characteristics. PCA, ANOSIM, and RDA were carried out within the $\mathrm{R}$ (3.4.1). The functions from the prokaryotic clades were predicted using FAPROTAX (Louca et al., 2016).

\section{RESULTS}

\section{Plant Aboveground Biomass and Soil Properties}

The BL soil received no plant biomass in the past 14 years (Table 1). The CL plots with maize generated the highest aboveground biomass about $24.80 \mathrm{~kg} \mathrm{plot}^{-1}$ every year (Table 1), but all of the aboveground biomass was removed from the field (Supplementary Figure S1). The annual incorporation of average aboveground biomass from 2004 to 2016 into soils of GL and AL was 10.00 and $9.67 \mathrm{~kg} \mathrm{plot}^{-1}$, respectively. The four long-term treatments have resulted in significant changes of soil properties (Table 1), which was closely related with the input of plant biomass (Supplementary Figure S1).

Compared with BL and CL, the content of SOC in GL and $\mathrm{AL}$ was significantly increased by $6.00-9.56 \mathrm{~g} / \mathrm{kg}(P<0.05)$. Similarly, the TN, EN, and AP contents of GL and AL were higher than those in BL and CL soils. The SOC, TN, and EN contents in $\mathrm{CL}$ treatment were not significantly higher than those in $\mathrm{BL}$ soil. Soil AP content was lower in CL relative to $\mathrm{BL}$, and the C:N ratio showed no significant differences among all the treatments. Soil $\mathrm{pH}$ values were the highest in GL soil (6.33) and the lowest in BL soil (5.75).

\section{Community Metabolisms of Carbon Substrates in Soil}

The GL and AL had the higher AWCDs throughout the incubation period $(P<0.05)$ (Figure 1A). PC1 and PC2 explained 56.59 and $16.78 \%$ of the variance in the data, respectively (Figure 1B). The treatments were divided into three groups based on the PCA scores. GL and AL treatments were grouped in the first quadrant; $\mathrm{CL}$ and $\mathrm{BL}$ treatments were separated in the other quadrants (Figure 1B). The results 
TABLE 1 | Soil properties and plant characteristics under different restoration managements of vegetation scenarios.

\begin{tabular}{|c|c|c|c|c|c|}
\hline & Items & BL & $\mathrm{CL}$ & GL & $A L$ \\
\hline \multirow[t]{6}{*}{ Soil } & $\operatorname{SOC}\left(\mathrm{g} \cdot \mathrm{kg}^{-1}\right)$ & $26.29 \pm 0.30^{c}$ & $26.77 \pm 0.58^{c}$ & $35.85 \pm 1.22^{a}$ & $32.77 \pm 0.28^{b}$ \\
\hline & $\mathrm{pH}$ & $5.75 \pm 0.05^{d}$ & $6.15 \pm 0.01^{b}$ & $6.33 \pm 0.04^{a}$ & $5.91 \pm 0.07^{c}$ \\
\hline & $\mathrm{TN}\left(\mathrm{g} \cdot \mathrm{kg}^{-1}\right)$ & $1.87 \pm 0.03^{b}$ & $1.98 \pm 0.10^{b}$ & $2.62 \pm 0.12^{a}$ & $2.51 \pm 0.07^{a}$ \\
\hline & $\mathrm{EN}\left(\mathrm{mg} \cdot \mathrm{kg}^{-1}\right)$ & $133.04 \pm 3.72^{c}$ & $137.21 \pm 6.76^{c}$ & $169.93 \pm 3.57^{a}$ & $159.82 \pm 4.49^{b}$ \\
\hline & $\mathrm{AP}\left(\mathrm{mg} \cdot \mathrm{kg}^{-1}\right)$ & $26.55 \pm 0.56^{C}$ & $16.01 \pm 3.56^{d}$ & $49.78 \pm 2.48^{a}$ & $43.11 \pm 3.45^{b}$ \\
\hline & $\mathrm{C} / \mathrm{N}$ & $14.04 \pm 0.13^{a}$ & $13.53 \pm 0.93^{a}$ & $13.67 \pm 0.26^{a}$ & $13.04 \pm 0.25^{a}$ \\
\hline \multirow[t]{4}{*}{ Plant } & Biomass $\left(\mathrm{kg} \cdot \mathrm{plot}^{-1}\right)$ & - & $24.80 \pm 1.12^{a}$ & $10.00 \pm 1.76^{b}$ & $9.67 \pm 0.67^{b}$ \\
\hline & $\mathrm{C}\left(\mathrm{g} \cdot \mathrm{kg}^{-1}\right)$ & - & $45.49 \pm 0.42^{b}$ & $44.30 \pm 0.35^{c}$ & $47.03 \pm 0.60^{a}$ \\
\hline & $\mathrm{N}\left(\mathrm{g} \cdot \mathrm{kg}^{-1}\right)$ & - & $0.93 \pm 0.06^{c}$ & $1.55 \pm 0.06^{b}$ & $2.02 \pm 0.06^{a}$ \\
\hline & $\mathrm{C}: \mathrm{N}$ & - & $49.28 \pm 3.62^{a}$ & $28.66 \pm 0.85^{b}$ & $23.33 \pm 0.81^{c}$ \\
\hline
\end{tabular}

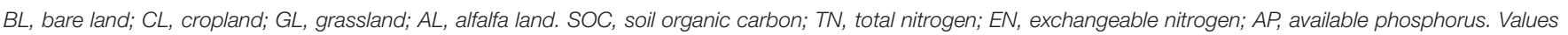

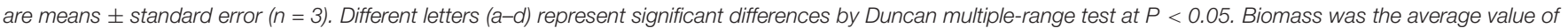

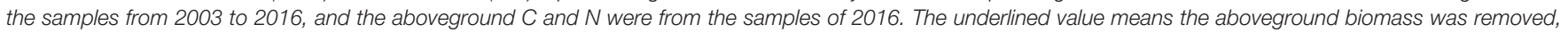
C, N, and C:N. - stands for not determined.

from the sixth day of incubation showed that the relative utilization rates of carbohydrates $\left(r^{2}=0.6205, P<0.01\right)$, phenolic compounds $\left(r^{2}=0.6411, P<0.01\right)$, amino acids $\left(r^{2}=0.5947, P<0.017\right)$, and amines $\left(r^{2}=0.5175, P<0.05\right)$ were stimulated significantly in GL and AL treatments relative to $\mathrm{CL}$ and BL soils (Figure 1C). Although the GL and AL treatments had similar metabolic patterns, the colors on substrates Dmannitol, D-cellobiose, D-galactonic acid g-lactone, itaconic acid, D-malic acid, D-galacturonic acid, L-serine, Tween 40, and 4hydroxybenzoic acid were more intensive in GL than that in $\mathrm{AL}$ $(P<0.05)$ (Figures 1B,C).

\section{Population Dynamic of Microbial Communities in Soil}

High-throughput sequencing resulted in high-quality sequences from 19,159 to 25,431 for each sample, and 19, 159 sequences were selected for normalization in each sample for subsequent analysis. The keystone taxa were defined as the phylum or genus showing statistically significant increase in relative abundance in soil samples of CL and GL relative to BL control soils (Figure 3). Real-time qPCR revealed higher copy numbers of the 16S rRNA genes in GL and AL than that in BL treatment (Figure 2A).

Bacteroidetes was the only keystone phylum with significant higher abundance in $\mathrm{AL}(4.81 \%)$ than other treatments $(P<0.05)$ as shown in Figure 2B. At the level of phylum, the dominant bacterial groups were Proteobacteria, Actinobacteria, Acidobacteria, and Chloroflexi with a relative abundance of $>5 \%$ in all three land use types (Figure 2B). The most dominant bacterial phyla were Proteobacteria $(31.73 \%)$ in $\mathrm{AL}$ treatment and Actinobacteria (26.38-28.53\%) in the other treatments (Figure 2B). No statistically significant difference in abundance of Acidobacteria was discovered among all the treatments $(P>0.01)$. The relative abundances of Firmicutes and Cyanobacteria were significantly declined by 74.53 and $84.71 \%$ in GL and by 68.63 and $69.42 \%$ in AL, respectively $(P<0.05)$, compared to that in BL (Supplementary Figure S2). The relative abundances of Gemmatimonadetes were not significantly different between $\mathrm{CL}$ and $\mathrm{BL}$, and they were significantly reduced in $\mathrm{AL}$ and GL, respectively, compared to that in BL. Hierarchical clustering and a PCoA plot with Bray_curtis matrix demonstrated that the microbial communities from the four treatments formed distinct groups (Figure 2C), which was further supported by beta diversity by Jaccard (Figure 2D) BrayCurtis (Figure 2E) matrix showing community shift in different soils at OTU level.

We identified indicative genera during ecological restoration by changes in relative abundance. A total of 490 genera were detected in samples among all treatments (Figure 3), and the relative abundances of 53, 106, and 120 genera were significantly increased in soils of CL (Figure 3A), GL (Figure 3B), and AL (Figure 3C) treatments, respectively, compared to that in BL soil. Meanwhile, 32, 57, and 39 genera showed significant declines in the soils of CL, GL, and $\mathrm{AL}$ treatments, respectively. In GL and $\mathrm{AL}$, the number of group with significantly increased relative abundance at the phylum level was higher than CL. Proteobacteria was the phylum with the highest relative abundance increase in all treatments. The genera with the highest increase in relative abundance were Bradyrhizobium, Ramlibacter, Piscinibacter, and Roseiflexus in CL and Bradyrhizobium, Solirubrobacter, Nocardioides, Acidibacter, and Rhodoplanes in GL and Bradyrhizobium, Acidibacter, Pseudarthrobacter, Nocardioides, and Flavobacterium AL. Clustering analysis further revealed that the keystone genera classified GL and AL soil into one group, whereas $\mathrm{CL}$ and $\mathrm{BL}$ formed the other group, regardless of the relative abundance of greater or less than $0.5 \%$, respectively (Figure 3D). Among these enriched genera, Gaiella, Microlunatus, RB41, Candidatus Solibacter, Bryobacter, Nitrospira, and Roseiflexus were dominant in all treatments (Figure 3D). The lowest relative abundance of Bradyrhizobium $(0.76 \%)$ and the highest relative abundance of Bacillus (2.35\%), Candidatu Solibacter (2.11\%), Massilia (1.16\%), Rhizomicrobium, and H16 were observed in the BL treatment. Reyranella, Mesorhizobium, Devosia, Haliangium, Nocardioides, and Pseudonocardia were significantly more abundant in GL and AL than that in CL and BL. Variibacter, Phenylobacterium, Skermanella, Piscinibacter, Azohydromonas, 
A

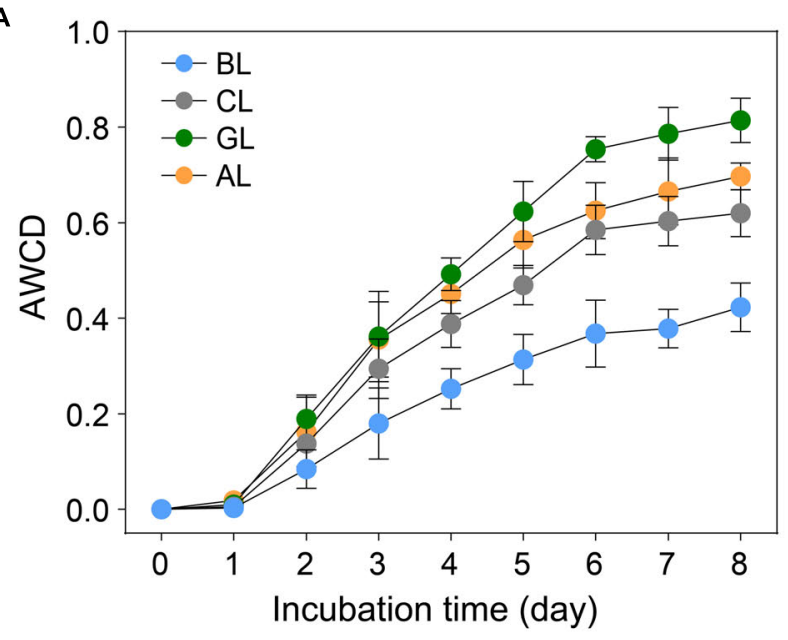

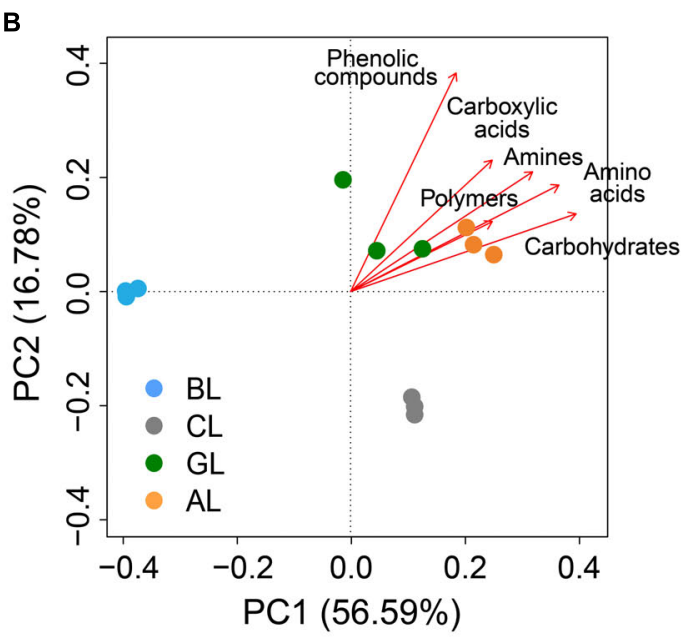

C

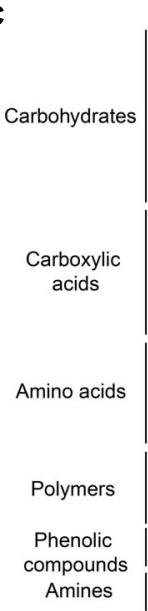

BL

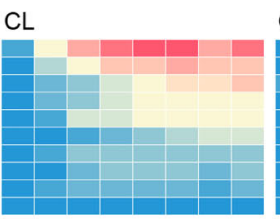

GL
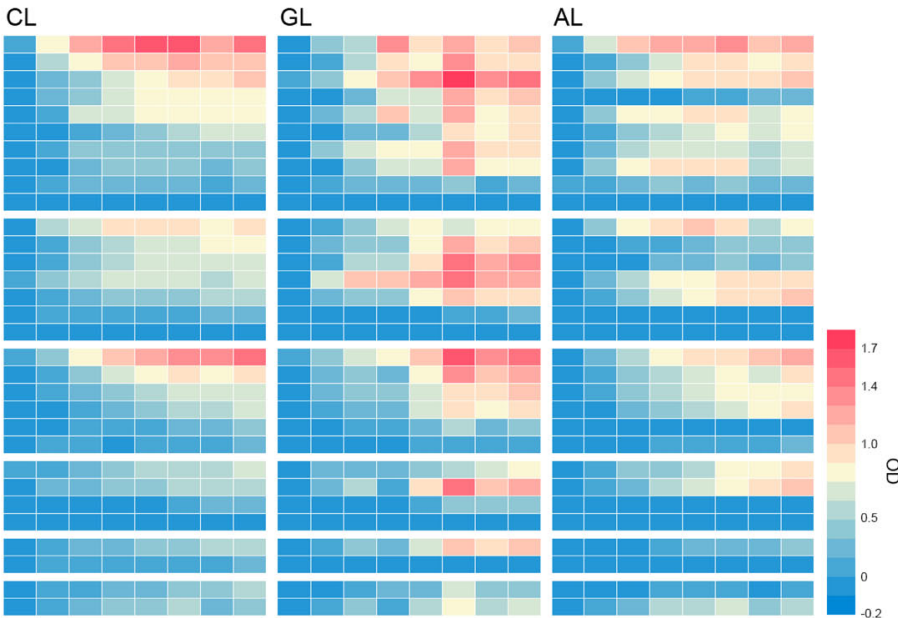

8

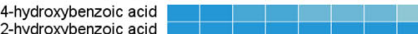

ethylamine
putrescine
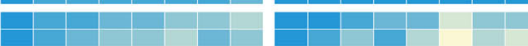

Incubation time (day)

FIGURE 1 | Community-level patterns of microbial carbon metabolism by Biolog EcoPlate in soils under different restoration managements. (A) Carbon utilization intensities for six different substrates of carbon compounds as indicated by AWCD values (average well color development) in soils; (B) principal component analysis (PCA) showing the community-level physiological profiling patterns of carbon utilization in different soils; (C) temporal dynamics of carbon utilization intensity on 31 different substrates (Biolog EcoPlate) by microbial communities in soils under different restoration managements. BL, bare land; CL, cropland; GL, grassland; AL, alfalfa plantation.

Acidibacter, Arenimonas, Steroidobacter, and Lysobacter were significantly more abundant only in AL, while less abundant in BL. Bacillus were reduced 2. 05-, 5. 15-, and 3.57-fold in the CL, $\mathrm{GL}$, and $\mathrm{AL}$, respectively, compared to that in BL.

\section{Relationships Between Microbial Community Composition and Soil Properties}

The overall structures of microbial communities in different treatments were significantly linked to the soil properties (Figure 4). RDA ordination analysis resulted in three distinct groups. The treatments of AL and GL were grouped into a cluster, whereas the treatments of $\mathrm{BL}$ and $\mathrm{CL}$ formed two control clusters, respectively. The main factors that grouped the treatments of $\mathrm{AL}$ and GL were SOC, TN, and EN. Meanwhile, cluster of BL samples appeared to be mostly influenced by $\mathrm{pH}$. Cluster of CL samples in turn was significantly affected by the content of AP. SOC content was the most influential soil property $(P<0.01)$ for the microbial communities, followed by $\mathrm{pH}(P<0.01)$ and AP content $(P<0.01)$.

\section{DISCUSSION}

The purpose of the present study was to decipher the keystone taxa showing significant increases in the degraded agricultural soil under different restoration regimes and to elucidate the changes in soil characteristics that could have affected community-level carbon metabolisms and keystone microbiomes in soils during a 14-year field experiment. Our results provided compelling evidences that the functional activity 


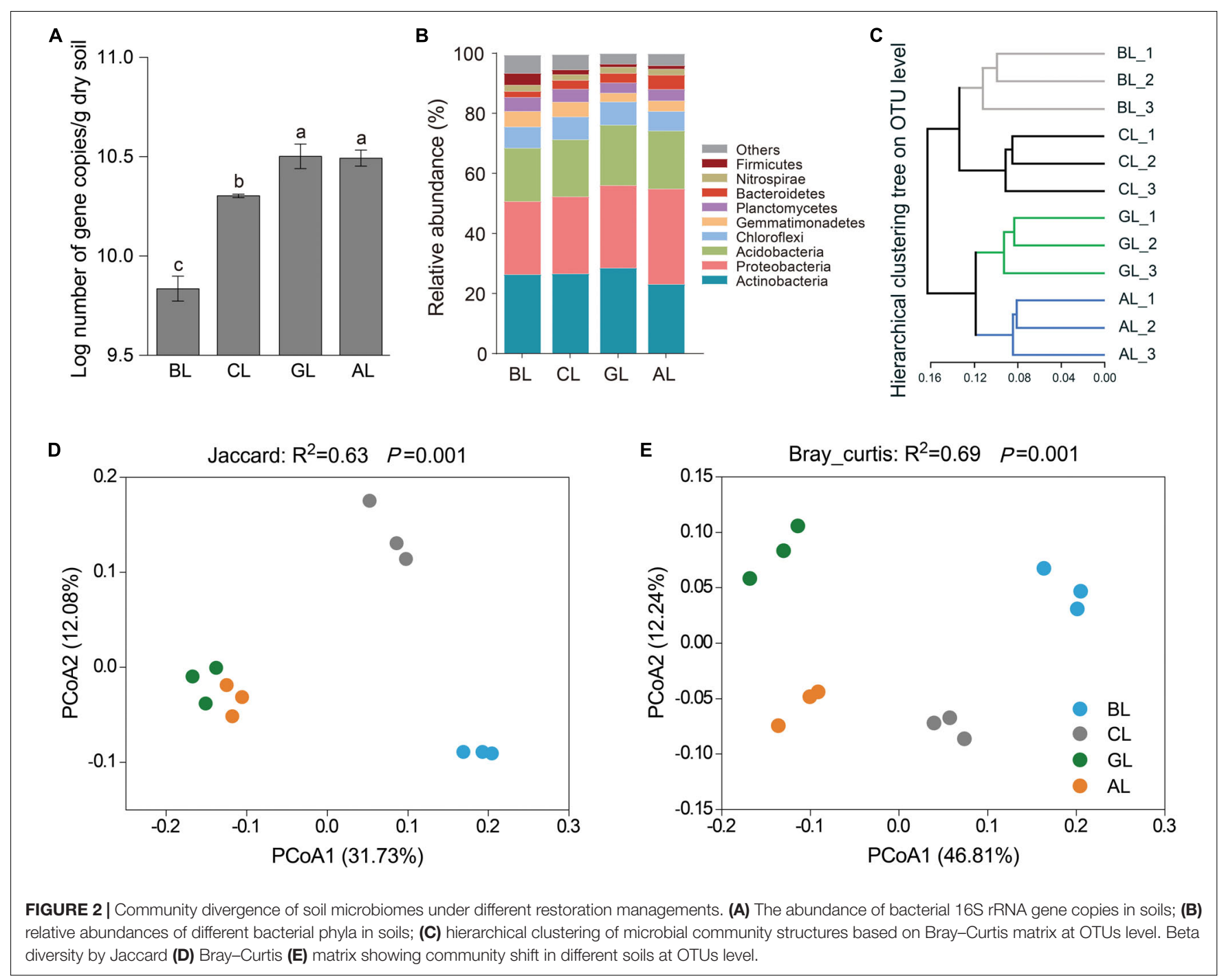

and composition of soil microbial communities during the restoration of $\mathrm{BL}$ to $\mathrm{CL}, \mathrm{AL}$, and GL were driven by changes in soil properties that were directly associated with the input and decomposition of plant biomass.

\section{Restoration of Soil Fertility Under Different Vegetation Regimes}

Our study revealed that the selected soil properties SOC, $\mathrm{pH}$, $\mathrm{TN}, \mathrm{EN}$, and AP were improved during the conversion from $\mathrm{BL}$ to $\mathrm{CL}$, AL, and GL $(P<0.05)$. Our study showed that GL and AL had greater SOC, $\mathrm{pH}, \mathrm{TN}, \mathrm{EN}$, and AP content than those in BL and CL. The SOC and TN content in $\mathrm{AL}$ increased by 24.65 and $36.36 \%$ and in GL by 34.22 and $40.10 \%$, respectively, when compared to that in BL. In our study, a large amount of aboveground biomass of grass (10.0 kg plot $\left.{ }^{-1}\right)$ and alfalfa (9.67 $\mathrm{kg} \mathrm{plot}^{-1}$ ) were input to the GL and AL, respectively, whereas those were moved out from the $\mathrm{BL}$ and CL (Table 1 and Supplementary Figure S1). In addition, annual crops invest less in root systems than do the perennial plants, with root biomass generally accounting for 5-30\% of the total plant biomass for many crops, including wheat and maize (Wu et al., 2011; Wang et al., 2014). Thus, the improved content of SOC might be attributed to the recovery of aboveground and underground biomass of plants and the decrease of tillage disturbance, which directly increase the inputs of organic C from aboveground tissues, roots, and root exudates into the soil and reduce the loss of SOC caused by disturbance of the soil (Romkens et al., 1999; Hao et al., 2017; Kantola et al., 2017; Liao et al., 2018). This result is largely consistent with that of Machmuller et al. (2015) in the southeastern United States, who found similar increases in SOC content after 6 years of changing a cropland to grassland. The grassland GL soil had significantly higher SOC contents than that of alfalfa after 14 years of experiment in the present study. By contrast, no significant difference in SOC contents was found in the conversion from cropland to alfalfa and grass for 2 years (Yu et al., 2017). Thus, the restoration duration is also an important factor affecting the soil nutrient contents (Guo et al., 2018). The lowest $\mathrm{pH}$ was observed in $\mathrm{BL}$, which could be explained by the excessive 
A
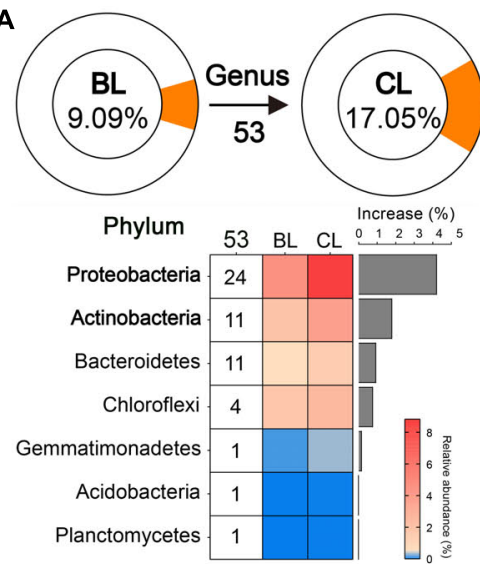

B

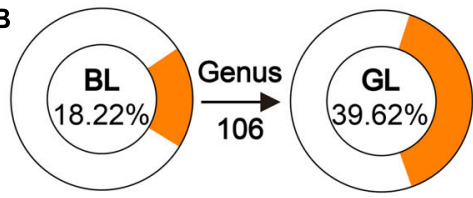

Phylum

Proteobacteria

Acidobacteria

Actinobacteria

Bacteroidetes

Chloroflexi

Latescibacteria

Planctomycetes

Chlorobi

Firmicutes

Increase (\%)
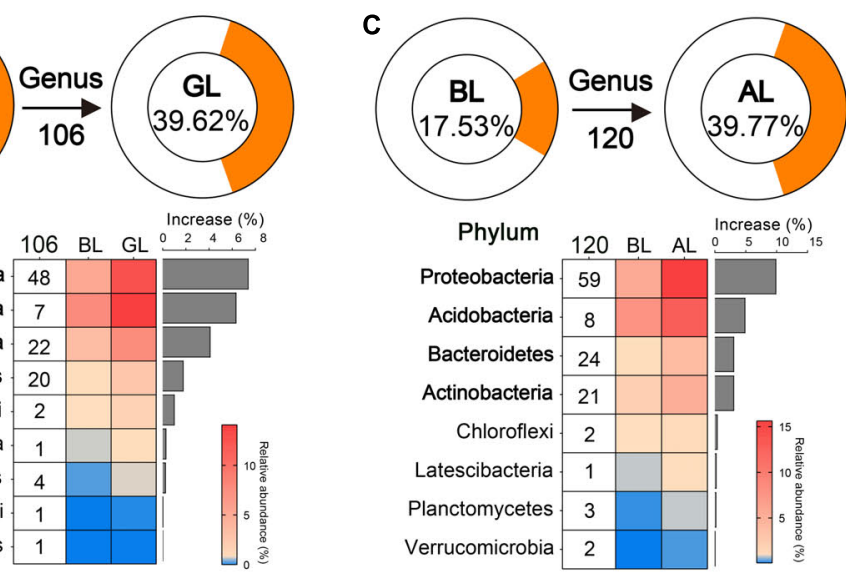

Phylum

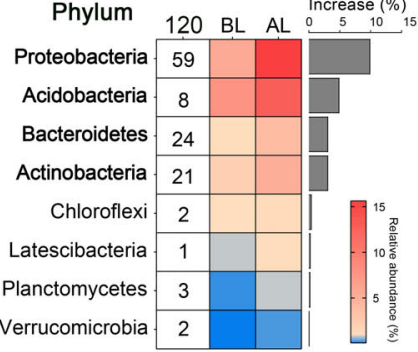

D
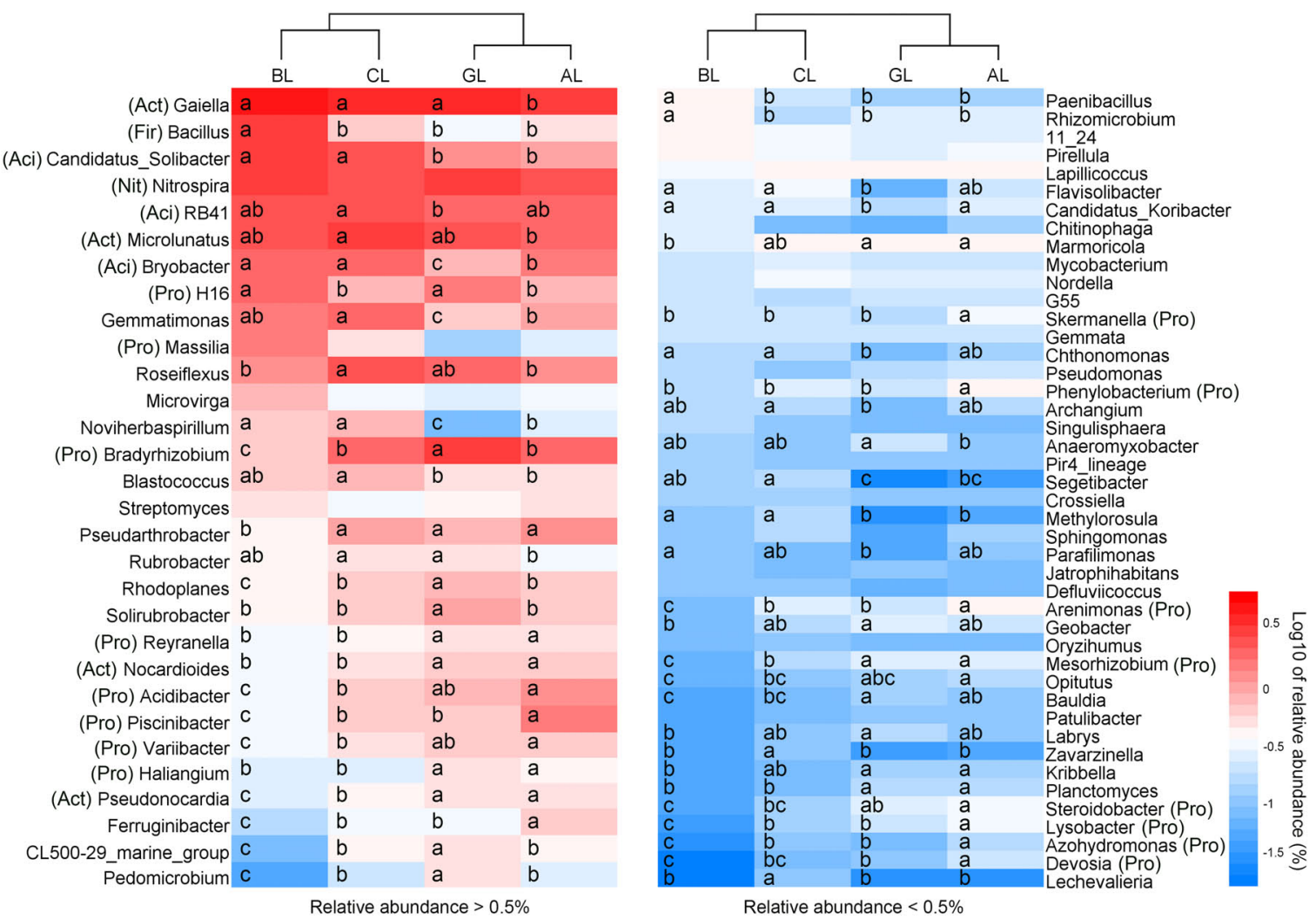

FIGURE 3 | Keystone taxa showing significant changes at genus level in soils under different restoration managements. Keystone taxa are defined as the phylotype whose relative abundance showed statistically significant increase in soils of $C L(\mathbf{A}), G L(\mathbf{B})$, and $A L$ (C) when compared with control bare soil BL. The portion in brown of the ring diagram represents total abundance of all keystone taxa, and the value below the arrow indicates the number of keystone taxa. These keystone genera are further classified into different phyla in the heatmap under the ring diagram. For example, a total of 53 genera of 7 phyla in $\mathrm{CL}$ soil showed significant increase relative to $\mathrm{BL}$ soil, and the total abundance of these 53 genera is 9.09 and $17.05 \%$ in $\mathrm{BL}$ and CL soils, respectively. The net increase in relative abundance of all 24 keystone genera within Proteobacteria phylum in $\mathrm{CL}$ soil is $4.23 \%$ when compared to those in BL soil. (D) Changes in relative abundances of keystone taxa in soils under different restoration managements. The heatmap in left and right sides represents the keystone genera with relative abundance greater and less than $0.5 \%$, respectively. Different letters $(\mathrm{a}-\mathrm{d})$ represent significant differences by Duncan multiple-range test at $P<0.05$.

application of mineral fertilizers and the continuous removal of base cations by crop harvest (Guo et al., 2010). Compared to $\mathrm{BL}$, soil $\mathrm{pH}$ in our study was also significantly higher in GL and $\mathrm{AL}$, perhaps due to the accumulation of large quantities of biomass as well (Bolan et al., 1991). Differences among the soil properties induced by distinct cover crop influence 


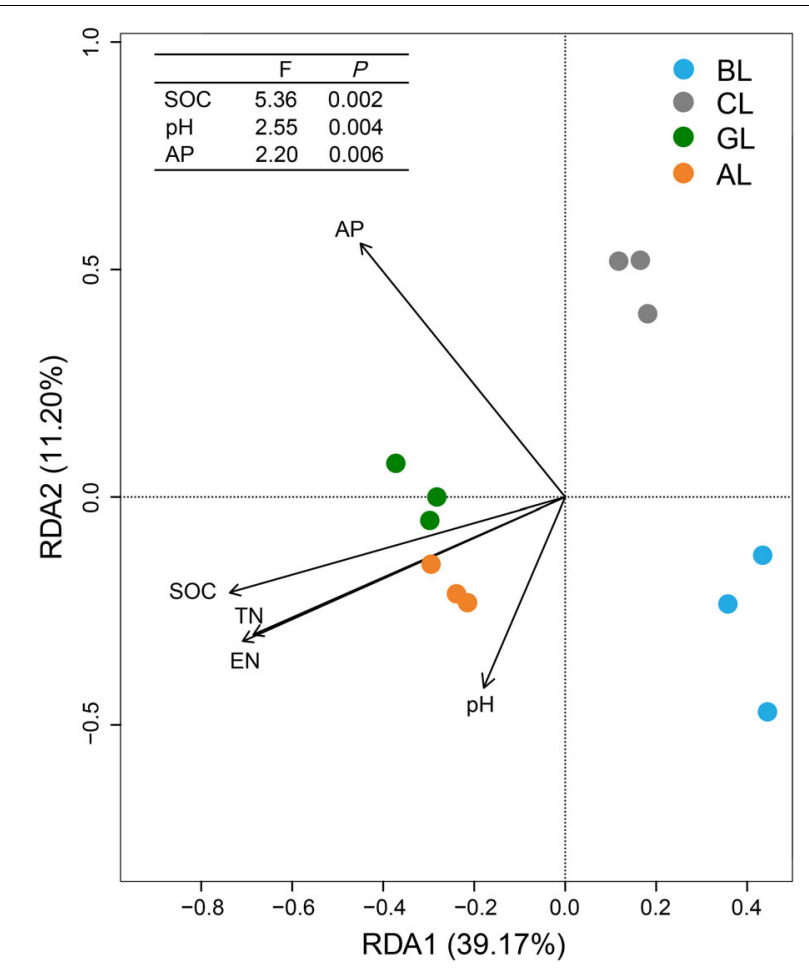

FIGURE 4 | Redundancy analysis (RDA) showing relationships between soil physiochemical characteristics and microbial communities. SOC, soil organic carbon; TN, total nitrogen; EN, exchangeable nitrogen; AP, available phosphorus.

the structures of microbial communities (Lauber et al., 2008). Therefore, vegetation has played an important role in controlling cropland degradation through adjusting soil nutrient level (such as SOC and $\mathrm{pH}$ ) in favor of microbial growth (Singh and Singh, 2006; Shrestha and Lal, 2010).

\section{Identification of Keystone Taxa in Soils Under Different Restoration Regimes}

The changed soil microbial community structure in AL and GL were attributed to changes in soil properties and vegetation, which could alter the microenvironment of microbes in soil (Finney et al., 2017). It has been reported that high plant diversity could increase the entering of different litters and root exudates to the soil and generate higher amounts of readily accessible C substrate to feed soil microorganisms (Wardle, 2006; Zhu et al., 2010).

Bacteroidetes is the only keystone taxa at phylum level showing significant increase in relative abundance in AL soils when compared to other treatments (Figure 2B). It includes 24 keystone genera (Figure 3C). For example, relative abundance of Ferruginibacter was $0.186 \%$ in BL, whereas relative abundance of these genera increased by more than two times in CL and GL and more than three times in AL. Relative abundance of Segetibacter was 0.15 and $0.19 \%$ in BL and CL. However, relative abundance of Segetibacter was only 0.02 and $0.05 \%$ in GL and AL. This result may reflect the fact that each microbial group has the best adapted environment and with capacity to bloom under favorable conditions. At the level of phylum, ecological restoration did not change the dominant phyla of the soil bacterial community, but their relative abundances were significantly altered (Figure 2B and Supplementary Figure S2). The dominant bacterial phyla, including Proteobacteria, Actinobacteria, and Acidobacteria, were in line with those in previous studies (Liu et al., 2014; Ding et al., 2016; Chen et al., 2020). Compared with the BL community, the relative abundance of Proteobacteria increased by $30.42 \%$, whereas that of Actinobacteria decreased by $12.36 \%$ in the $\mathrm{AL}$, and the relative abundance of Proteobacteria and Actinobacteria increased by 13.19 and $8.15 \%$ in the GL, respectively. Proteobacteria and Actinobacteria are usually regarded as copiotrophic microbes that existed in soil under sufficient nutrient conditions, and they play important roles in the soil carbon cycle (Fierer et al., 2007; Zhang et al., 2016). Thus, it can be concluded that the transition in the relative abundance of Proteobacteria and Actinobacteria after land-use conversion could be a result of increase in soil nutrients (SOC and pH) (Table 1, Figure 4, and Supplementary Table S2). In the present study, restoration (GL and $\mathrm{AL}$ ) decreased the relative abundances of Cyanobacteria and Firmicutes compared with that in BL. Bacteria in these two phyla are commonly believed as oligotrophic groups occurring in low nutrients and disturbed soil (De Deyn and Van Der Putten, 2005; Barnard et al., 2013). In contrast, Trivedi et al. (2016) summarized previous studies and indicated that natural revegetation increases abundance of Cyanobacteria and decreases abundance of Firmicutes. The decrease of Cyanobacteria (photoautotrophs) could be related to the decrease of sunlight availability in soil due the increasing vegetation coverage (Zhang et al., 2018). Additionally, previous report showed that alfalfa cultivation can decrease the number and Shannon index of Cyanobacteria species in soil, because alfalfa roots release various flavonoids that can substantially affect growth and physiological functions of Cyanobacteria species (Huang et al., 2015; Alghanmi and Jawad, 2019). Lower photosynthetic carbon sequestration group (belonging to Cyanobacteria) appeared in GL and AL 4.78- and 2.25-fold, respectively, greater than that in BL (Supplementary Table S1). Therefore, further researches are needed to address the discrepancy, which might probably be attributed to the different vegetation restoration types, climate, and soil fertility.

A number of genera within dominant phyla were identified as keystone taxa, although no significant increase was observed for the dominant taxa at phylum level except for Bacteroidetes. A number of $\mathrm{N}_{2}$ fixers were found to be keystone genera showing significantly higher abundance in GL and AL soils than BL and CL soils, including Bradyrhizobium, Devosia, Mesorhizobium, and Azohydromonas. These nif gene-containing keystone taxa can fix nitrogen and promote plants growth (Franche et al., 2009; Martínez-Hidalgo and Hirsch, 2017). In addition, the quality and quantity of aboveground litter and belowground roots supplied to the soil differed greatly in GL and $\mathrm{AL}$ and presumably stimulated the abundance of Nocardioides significantly in association with the accelerated decomposition of xylan (Whitman et al., 2012). Steroidobacter was significantly more abundant in AL treatment and may contribute to the 
mineralization of soil organic matter to meet the $\mathrm{N}$ demand of plants (Lian et al., 2017). Alfalfa, a leguminous plant, can affect the nitrogen cycle in soil. The genera associated with the nitrogen cycle (Garrity, 2005; Fahrbach et al., 2008; Yuan et al., 2014), such as Skermanella, were highly abundant only in $\mathrm{AL}$ treatment (Figure 3D). The relative abundances of Bacillus, Rhizomicrobium, and Paenibacillus were significantly higher in BL treatment than in other treatments. All of these genera were capable of diverse functions, such as Plant Growth Promoting Rhizobacteria (PGPR), nitrogen fixation, and litter decomposition. In fact, Bacillus members are well known to survive in harsh environments (Tao et al., 2015). We speculated that the oligotrophic environment in BL could have selectively stimulated the growth and enhanced the relative abundance of Bacillus. Compared with that in BL soil, the relative abundance of Bacillus was lower in CL, GL, and AL treatments 2. 05-, 5. 15-, and 3.57-fold, respectively (Figure 3D). It thus implies that Bacillus might serve as an indicator of agricultural land degradation. Stable-isotope probing of functional processes such as nitrogen fixation would be of help toward better understandings of dynamic changes of keystone taxa in soils such as Rhizomicrobium and Paenibacillus under distinct restoration scenario of the degraded agricultural land.

\section{Community Metabolism of Carbon Substrates in Soils}

The land restoration not only selected for distinct keystone microbiomes but also affected metabolic functions of microbial communities in soils. The $\mathrm{C}$ metabolism (Figure 1) of total bacteria in GL and AL treatments was significantly higher than those in CL and BL treatments. Soil microbial communities in GL and AL exhibited CLPPs different from those in CL and BL, indicating their different $C$ substrate preferences (Figure 1B). The microbial communities in GL and AL were more efficient in using carbohydrates, phenolic compounds, amino acids, and amines than those in $\mathrm{BL}$ and CL. The potential causes of this discrepancy are the following: (1) the different inputs of aboveground/root biomass and type/amount of root exudates could affect the total abundance of microbial communities (Figure 2A), which in turn lead to distinct decomposition capability in various treatments; (2) disturbed agricultural managements or tillage could affect the heterotrophic activities of soil microbial communities by altering the aeration of the soil body and contact between the SOC and microbes. Under the condition of undisturbed ecological recovery, the plant microbial community interaction was stronger in GL and AL than that in $\mathrm{CL}$ and BL soils, because the plant residues in the soil stimulated the proliferation of chemoheterotrophic groups, which increased the metabolic capacity of the microbial community and ultimately improved the soil health and ecosystem function (Alcoze et al., 2000; Izquierdo et al., 2005). In GL treatment, the utilization intensity of D-cellobiose, itaconic acid, D-malic acid, and 4-hydroxybenzoic acid was higher in GL than AL, which can be attributed to the higher plant diversity of grassland. In addition, the relative abundance of chemoheterotrophic microbes in GL was significantly higher than that in AL (Supplementary
Table S1). The nutrient contents of BL as a degraded soil were not different from that of CL treatment, whereas the metabolic capacity, the amount of carbon source utilization, and the relative abundance of chemoheterotrophic microbes in CL treatment were significantly higher than those in $\mathrm{BL}$ treatment, indicating that CLPP can be a useful indicator of soil degradation/restoration. Further studies linking the specific physiology of carbon metabolism to the taxonomic identity of active keystone taxa are warranted.

\section{Linking Soil Characteristics With Keystone Taxa in Soils}

In the present study, keystone taxa were identified (Figure 3), and dynamic changes of keystone microbiomes were assessed in association with multiple environmental factors (Figure 4 and Supplementary Table S2). RDA ordination indicated that soil SOC content, $\mathrm{pH}$, and AP played dominant roles in shaping the microbial community composition (Figure 4). This observation was contradictory to previous findings that $\mathrm{pH}$ was the key factor regulating the structures of bacterial community in soils (Cao et al., 2017), both on large and fine scales (Shen et al., 2013). Meanwhile, it has been shown that SOC was the best predictor for microbial community structure in soils across different agricultural land management at a given location (Sul et al., 2013). Our study revealed that the relative abundances of Proteobacteria, Firmicutes, and Cyanobacteria were significantly correlated with most of the measured soil properties (Supplementary Table S2). The soil characteristics SOC, TN, and EN had significantly positive correlations with Proteobacteria and had no significant correlations with Actinobacteria and Acidobacteria (Supplementary Table S2). Cyanobacteria and Firmicutes are the less abundant bacterial phyla in terrestrial habitats and are negatively related with SOC, pH, TN, and EN (Supplementary Table S2). Firmicutes are very important to decompose the vegetable litter (Nuccio et al., 2013; Cui et al., 2019). Compared to BL soil, GL and AL soils showed dramatic decrease in abundance of Firmicutes, implying that the members of which were not important in the composition of plant residues/litters, being consistent with the recent findings (Cui et al., 2019) that microbial community shifts during the conversion of the cropland to brushland. Despite the correlative analysis, long-term field experiment represents a net result of microbial community changes over 14 years and very likely reflects what is occurring under the field conditions. But it remains unclear to what extent these decreasing phylotypes could represent the progressive degradation of agricultural land under intensive anthropogenic interference. Future studies with isolates of target keystone taxa can provide more information on the ecophysiology of functional microbiome in restoring the degraded agricultural land.

\section{CONCLUSION}

This study demonstrated that grassland vegetation (GL) and alfalfa planting (AL) could significantly enhance soil fertility after 14 years of ecological restoration. The relative abundances 
of dominant phyla showed significant changes, although the composition of soil microbiome remained largely unchanged. The relative abundance of the key taxa, such as genera of Reyranella, Mesorhizobium, Devosia, Haliangium, Nocardioides, and Pseudonocardia, were significantly more abundant in GL and AL. The relative abundance of Bacillus was significantly higher in the BL than other treatments. Bacillus (Firmicutes) and Cyanobacteria genus showed significant decrease in abundance in the GL and AL soils when compared to BL soil. These two taxa can be considered as bioindicators of agricultural land degradation. Furthermore, RDA and correlation analysis revealed that the SOC content was the primary factor determining the population dynamics changes of keystone microbiomes during ecological restoration. Overall, this study provides insights into the keystone microbiomes associated with decomposition of plant biomass and the carbon source metabolism of microbial communities in degraded black soil under different restoration scenarios in northeastern China.

\section{DATA AVAILABILITY STATEMENT}

The datasets generated for this study can be found in the NCBI under accession number: PRJNA588746.

\section{AUTHOR CONTRIBUTIONS}

JY designed the study. ZZ and XC performed the work. $\mathrm{XH}$ and $\mathrm{XL}$ analyzed the data. EW and $\mathrm{WZ}$ revised the manuscript. All authors read and approved the final manuscript.

\section{REFERENCES}

Alcoze, T. A., Covington, W. W., and Fulé, P. Z. (2000). Restoration ecology. Science 287:2159. doi: 10.1126/science.287.5461.2159b

Alexander, G. G., and Allan, J. D. (2007). Ecological success in stream restoration: case studies from the midwestern United States. Environ. Manag. 40, 245-255. doi: 10.1007/s00267-006-0064-6

Alghanmi, H. A., and Jawad, H. M. (2019). Effect of environmental factors on cyanobacteria richness in some agricultural soils. Geomicrobiol. J. 36, 75-84. doi: 10.1080/01490451.2018.1517196

Audino, L. D., Louzada, J., and Comita, L. (2014). Dung beetles as indicators of tropical forest restoration success: is it possible to recover species and functional diversity? Biol. Conserv. 169, 248-257. doi: 10.1016/j.biocon.2013.11.023

Barnard, R. L., Osborne, C. A., and Firestone, M. K. (2013). Responses of soil bacterial and fungal communities to extreme desiccation and rewetting. ISME J. 7, 2229-2229. doi: 10.1038/ismej.2013.104

Bindraban, P. S., van der Velde, M., Ye, L. M., van den Berg, M., Materechera, S., Kiba, D. I., et al. (2012). Assessing the impact of soil degradation on food production. Curr. Opin. Environ. Sustainabil. 4, 478-488. doi: 10.1016/j.cosust. 2012.09.015

Bolan, N. S., Hedley, M. J., and White, R. E. (1991). Processes of soil acidification during nitrogen cycling with emphasis on legume based pastures. Plant Soil 134, 53-63. doi: 10.1007/bf00010717

Bossio, D. A., Girvan, M. S., Verchot, L., Bullimore, J., Borelli, T., Albrecht, A., et al. (2005). Soil microbial community response to land use change in an agricultural landscape of Western Kenya. Microb. Ecol. 49, 50-62. doi: 10.1007/s00248-0030209-6

\section{FUNDING}

This study was funded by the National Natural Science Foundation of China $(41771327 ; 41671299)$. EW was financially supported by the project SIP 20195271 authorized by Instituto Politécnico Nacional, Mexico.

\section{SUPPLEMENTARY MATERIAL}

The Supplementary Material for this article can be found online at: https://www.frontiersin.org/articles/10.3389/fmicb. 2020.01915/full\#supplementary-material

FIGURE S1 | The annual input of aboveground biomass under different restoration of vegetation managements from 2004 to 2016. The abbreviation of $\mathrm{BL}$ denotes that the degraded bare land receiving no plant-associated matter as the vegetation of wild grass was removed whenever emerged. The abbreviation of $\mathrm{CL}$ indicates that the maize (Zea mays L.) land receiving no fertilizer andall aboveground biomass of maize was removed every year. The abbreviations of GL and $A L$ represent the vegetation treatments of natural grassland and alfalfa plantation, and the biomass of 10.00 and $9.67 \mathrm{~kg} \mathrm{plot}^{-1}$, respectively, were returned to the field for natural restoration and alfalfa plantation. The CL_(1) refers to the healthy land with maize crop under traditional fertilization managements, and it shows the highest aboveground biomass about $42.74 \mathrm{~kg} \mathrm{plot}^{-1}$ every year. $\mathrm{BL}$, bare land; $\mathrm{CL}$, cropland; $\mathrm{CL}$ (1), cropland with traditional fertilization management; GL, grassland; AL, alfalfa plantation.

FIGURE S2 | Relative abundances of bacterial phyla under different restoration managements. Different letters (a-c) represent significant differences by Duncan's multiple range test at $P<0.05$.

TABLE S1 | Relative abundance of predicted function groups based on FAPROTAX database.

TABLE S2 | Correlations between soil properties and the relative abundance of the main phyla and genera.

Cao, C., Zhang, Y., Qian, W., Liang, C., Wang, C., and Tao, S. (2017). Landuse changes influence soil bacterial communities in a meadow grassland in Northeast China. Solid Earth 8, 1119-1129. doi: 10.5194/se-8-11192017

Chen, L., Jiang, Y., Liang, C., Luo, Y., Xu, Q., Han, C., et al. (2019). Competitive interaction with keystone taxa induced negative priming under biochar amendments. Microbiome 7:77. doi: 10.1186/s40168-0190693-7

Chen, L., Li, F., Li, W., Ning, Q., Li, J., Zhang, J., et al. (2020). Organic amendment mitigates the negative impacts of mineral fertilization on bacterial communities in Shajiang black soil. Appl. Soil Ecol. 150:103457. doi: 10.1016/j.apsoil.2019. 103457

Chou, Y. M., Shen, F. T., Chiang, S. C., and Chang, C. M. (2016). Functional diversity and dominant populations of bacteria in banana plantation soils as influenced by long-term organic and conventional farming. Appl. Soil Ecol. 110, 21-33. doi: 10.1016/j.apsoil.2016.11.002

Clarke, K. R., and Ainsworth, M. (1993). A method of linking multivariate community structure to environmental variables. Mar. Ecol. Prog. Ser. 92, 205-219. doi: 10.3354/meps092205

Classen, A. T., Boyle, S. I., Haskins, K. E., Overby, S. T., and Hart, S. C. (2003). Community-level physiological profiles of bacteria and fungi: plate type and incubation temperature influences on contrasting soils. FEMS Microbiol. Ecol. 44, 319-328. doi: 10.1016/S0168-6496(03)00068-0

Cui, Y., Fang, L., Guo, X., Wang, X., Wang, Y., Zhang, Y., et al. (2019). Responses of soil bacterial communities, enzyme activities, and nutrients to agriculturalto-natural ecosystem conversion in the Loess Plateau, China. J. Soils Sediments 19, 1427-1440. doi: 10.1007/s11368-018-2110-4 
De Deyn, G. B., and Van Der Putten, W. H. (2005). Linking aboveground and belowground diversity. Trends Ecol. Evol. 20, 625-633. doi: 10.1016/j.tree.2005. 08.009

Deng, J., Bai, X., Zhou, Y., Zhu, W., and Yin, Y. (2020). Variations of soil microbial communities accompanied by different vegetation restoration in an open-cut iron mining area. Sci. Total Environ. 704:135243. doi: 10.1016/j.scitotenv.2019. 135243

Ding, J., Jiang, X., Ma, M., Zhou, B., Guan, D., Zhao, B., et al. (2016). Effect of 35 years inorganic fertilizer and manure amendment on structure of bacterial and archaeal communities in black soil of northeast China. Appl. Soil Ecol. 105, 187-195. doi: 10.1016/j.apsoil.2016.04.010

Donnison, L. M., Griffith, G. S., Hedger, J., Hobbs, P. J., and Bardgett, R. D. (2000). Management influences on soil microbial communities and their function in botanically diverse haymeadows of northern England and Wales. Soil Biol. Biochem. 32, 253-263. doi: 10.1016/s0038-0717(99)00159-5

Edgar, R. C. (2013). UPARSE: highly accurate OTU sequences from microbial amplicon reads. Nat. Methods 10, 996-998. doi: 10.1038/nmeth.2604

Edgar, R. C., Haas, B. J., Clemente, J. C., Quince, C., and Knight, R. (2011). UCHIME improves sensitivity and speed of chimera detection. Bioinformatics 27, 2194-2200. doi: 10.1093/bioinformatics/btr381

Fahrbach, M., Kuever, J., Remesch, M., Huber, B. E., Kampfer, P., Dott, W., et al. (2008). Steroidobacter denitrificans gen. nov., sp nov., a steroidal hormonedegrading gammaproteobacterium. Int. J. Syst. Evol. Microbiol. 58, 2215-2223. doi: 10.1099/ijs.0.65342-0

Fierer, N., Bradford, M. A., and Jackson, R. B. (2007). Toward an ecological classification of soil bacteria. Ecology 88, 1354-1364. doi: 10.1890/05-1839

Finney, D. M., Buyer, J. S., and Kaye, J. P. (2017). Living cover crops have immediate impacts on soil microbial community structure and function. J. Soil Water Conserv. 72, 361-373. doi: 10.2489/jswc.72.4.361

Foley, J. A., DeFries, R., Asner, G. P., Barford, C., Bonan, G., Carpenter, S. R., et al. (2005). Global consequences of land use. Science 309, 570-574. doi: 10.1126/ science. 1111772

Franche, C., Lindström, K., and Elmerich, C. (2009). Nitrogen-fixing bacteria associated with leguminous and non-leguminous plants. Plant Soil 321, 35-59. doi: 10.1007/s11104-008-9833-8

Furtak, K., Gawryjolek, K., Gajda, A. M., and Galazka, A. (2017). Effects of maize and winter wheat grown under different cultivation techniques on biological activity of soil. Plant Soil Environ. 63, 449-454. doi: 10.17221/486/2017-pse

Garland, J. L., and Mills, A. L. (1991). Classification and characterization of heterotrophic microbial communities on the basis of patterns of communitylevel sole-carbon-source utilization. Appl. Environ. Microbiol. 57, 2351-2359. doi: 10.1128/aem.57.8.2351-2359.1991

Garrity, G. M. (2005). “The Proteobacteria (Part C),” in Bergey's Manual\$of Systematic Bacteriology, Vol. Two, eds G. Garrity, D. J. Brenner, N. R. Krieg, and J. T. Staley, (Berlin: Springer).

Gong, H. L., Meng, D., Li, X. J., and Zhu, F. (2013). Soil degradation and food security coupled with global climate change in northeastern China. Chinese Geographical Sci. 23, 562-573. doi: 10.1007/s11769-013-0626-5

Guo, J. H., Liu, X. J., Zhang, Y., Shen, J. L., Han, W. X., Zhang, W. F., et al. (2010). Significant acidification in major chinese croplands. Science 327, 1008-1010. doi: 10.1126/science.1182570

Guo, Y., Chen, X., Wu, Y., Zhang, L., Cheng, J., Wei, G., et al. (2018). Natural revegetation of a semiarid habitat alters taxonomic and functional diversity of soil microbial communities. Sci. Total Environ. 635, 598-606. doi: 10.1016/j. scitotenv.2018.04.171

Hao, X., You, M., Han, X., Li, H., Zou, W., and Xing, B. (2017). Redistribution of different organic carbon fractions in the soil profile of a typical chinese mollisol with land-use change. Commun. Soil Sci. Plant Anal. 48, 2369-2380. doi: 10.1080/00103624.2017.1358741

Hou, X., Han, H., Tigabu, M., Cai, L., Meng, F., Liu, A., et al. (2019). Changes in soil physico-chemical properties following vegetation restoration mediate bacterial community composition and diversity in Changting, China. Ecol. Eng. 138, 171-179. doi: 10.1016/j.ecoleng.2019.07.031

Hou, X., Han, X., Li, H., and Xing, B. (2010). Composition and organic carbon distribution of organomineral complex in black soil under different land uses and management systems. Commun. Soil Sci. Plant Anal. 41, 1129-1143. doi: $10.1080 / 00103620903430016$
Huang, H., Xiao, X., Ghadouani, A., Wu, J., Nie, Z., Peng, C., et al. (2015). Effects of natural flavonoids on photosynthetic activity and cell integrity in Microcystis aeruginosa. Toxins 7, 66-80. doi: 10.3390/toxins7010066

Ilunga wa Ilunga, E., Mahy, G., Piqueray, J., Séleck, M., Shutcha, M. N., Meerts, P., et al. (2015). Plant functional traits as a promising tool for the ecological restoration of degraded tropical metal-rich habitats and revegetation of metalrich bare soils: a case study in copper vegetation of Katanga, DRC. Ecol. Eng. 82, 214-221. doi: 10.1016/j.ecoleng.2015.04.084

Izquierdo, I., Caravaca, F., Alguacil, M. M., Hernández, G., and Roldán, A. (2005). Use of microbiological indicators for evaluating success in soil restoration after revegetation of a mining area under subtropical conditions. Appl. Soil Ecol. 30, 3-10. doi: 10.1016/j.apsoil.2005.02.004

Jackson, M. L. (1973). Soil Chemical Analysis. New Delhi: Prentice Hall of India Pvt Ltd, 25-214.

Kantola, I. B., Masters, M. D., and DeLucia, E. H. (2017). Soil particulate organic matter increases under perennial bioenergy crop agriculture. Soil Biol. Biochem. 113, 184-191. doi: 10.1016/j.soilbio.2017.05.023

Lamers, L., Vile, M., Grootjans, A. P., Acreman, M., Diggelen, R., Evans, M., et al. (2014). Ecological restoration of rich fens in Europe and North America: from trial and error to an evidence-based approach. Biol. Rev. 90, 182-203. doi: 10.1111/brv.12102

Lauber, C. L., Strickland, M. S., Bradford, M. A., and Fierer, N. (2008). The influence of soil properties on the structure of bacterial and fungal communities across land-use types. Soil Biol. Biochem. 40, 2407-2415. doi: 10.1016/j.soilbio. 2008.05.021

Li, H., Han, X., Wang, F., Qiao, Y., and Xing, B. (2007). Impact of soil management on organic carbon content and aggregate stability. Commun. Soil Sci. Plant Anal. 38, 1673-1690. doi: 10.1080/00103620701435456

Lian, T., Jin, J., Wang, G., Tang, C., Yu, Z., Li, Y., et al. (2017). The fate of soybean residue-carbon links to changes of bacterial community composition in Mollisols differing in soil organic carbon. Soil Biol. Biochem. 109, 50-58. doi: 10.1016/j.soilbio.2017.01.026

Liao, H., Zheng, C., Li, J., and Long, J. (2018). Dynamics of soil microbial recovery from cropland to orchard along a 20-year chronosequence in a degraded karst ecosystem. Sci. Total Environ. 639, 1051-1059. doi: 10.1016/j.scitotenv.2018. 05.246

Liu, J., Sui, Y., Yu, Z., Shi, Y., Chu, H., Jin, J., et al. (2014). High throughput sequencing analysis of biogeographical distribution of bacterial communities in the black soils of northeast China. Soil Biol. Biochem. 70, 113-122. doi: 10.1016/j.soilbio.2013.12.014

Louca, S., Parfrey, L. W., and Doebeli, M. (2016). Decoupling function and taxonomy in the global ocean microbiome. Science 353, 1272-1277. doi: 10. 1126/science.aaf4507

Machmuller, M. B., Kramer, M. G., Cyle, T. K., Hill, N., Hancock, D., and Thompson, A. (2015). Emerging land use practices rapidly increase soil organic matter. Nat. Commun. 6:6995. doi: 10.1038/ncomms7995

Martínez-Hidalgo, P., and Hirsch, A. M. (2017). The nodule microbiome: $\mathrm{N}_{2}$ fixing rhizobia do not live alone. Phytobiomes 1, 70-82. doi: 10.1094/PBIOMES12-16-0019-RVW

Mendes, L. W., de Lima Brossi, M. J., Kuramae, E. E., and Tsai, S. M. (2015). Landuse system shapes soil bacterial communities in Southeastern Amazon region. Appl. Soil Ecol. 95, 151-160. doi: 10.1016/j.apsoil.2015.06.005

Meng, Q. J., Xu, Y. L., Li, C. J., Han, X. Z., and Pei, X. C. (2008). Effects of different vegetation coverage on microbial functional diversity in black soil. Chinese J. Ecol. 27, 1134-1140. doi: 10.13292/j.1000-4890.2008.0229

Nuccio, E. E., Hodge, A., Pett-Ridge, J., Herman, D. J., Weber, P. K., and Firestone, M. K. (2013). An arbuscular mycorrhizal fungus significantly modifies the soil bacterial community and nitrogen cycling during litter decomposition. Environ. Microbiol. 15, 1870-1881. doi: 10.1111/1462-2920.12081

Olsen, S. R. A., and Sommers, L. E. (1982). "Phosphorus," in Methods of Soil Analysis. Part 2: Chemical and Microbiological Properties, eds A. L. Page, R. H. Miller, and D. R. Keeney, (Madison: American Society of Agronomy, Inc), 403-427.

Page, A. L., Miller, R. H., and Keeney Dennis, R. (1982). Methods of soil analysis. Catena 15, 99-100.

Pankhurst, C. E., Kirkby, C. A., Hawke, B. G., and Harch, B. D. (2002). Impact of a change in tillage and crop residue management practice on soil chemical 
and microbiological properties in a cereal-producing red duplex soil in NSW, Australia. Biol. Fertil. Soils 35, 189-196. doi: 10.1007/s00374-002-0459-3

Parks, D. H., Tyson, G. W., Hugenholtz, P., and Beiko, R. G. (2014). STAMP: statistical analysis of taxonomic and functional profiles. Bioinformatics 30, 3123-3124. doi: 10.1093/bioinformatics/btu494

Quast, C., Pruesse, E., Yilmaz, P., Gerken, J., Schweer, T., Yarza, P., et al. (2013). The SILVA ribosomal RNA gene database project: improved data processing and web-based tools. Nucleic Acids Res. 41, D590-D596. doi: 10.1093/nar/gks1219

Romkens, P., van der Plicht, J., and Hassink, J. (1999). Soil organic matter dynamics after the conversion of arable land to pasture. Biol. Fertil. Soils 28, 277-284. doi: $10.1007 / \mathrm{s} 003740050494$

Rutgers, M., Wouterse, M., Drost, S. M., Breure, A. M., Mulder, C., Stone, D., et al. (2016). Monitoring soil bacteria with community-level physiological profiles using Biolog (TM) ECO-plates in the Netherlands and Europe. Appl. Soil Ecol. 97, 23-35. doi: 10.1016/j.apsoil.2015.06.007

Shen, C., Xiong, J., Zhang, H., Feng, Y., Lin, X., Li, X., et al. (2013). Soil pH drives the spatial distribution of bacterial communities along elevation on Changbai Mountain. Soil Biol. Biochem. 57, 204-211. doi: 10.1016/j.soilbio.2012.07.013

Shrestha, R. K., and Lal, R. (2010). Carbon and nitrogen pools in reclaimed land under forest and pasture ecosystems in Ohio, USA. Geoderma 157, 196-205. doi: 10.1016/j.geoderma.2010.04.013

Singh, A. N., and Singh, J. S. (2006). Experiments on ecological restoration of coal mine spoil using native trees in a dry tropical environment, India: a synthesis. New Forests 31, 25-39. doi: 10.1007/s11056-004-6795-4

Staff, S. S. (2014). Keys to Soil Taxonomy, 12th Edn. Washington, DC: Natural Resources Conservation Service, United States Department of Agriculture.

Su, J.-Q., Ding, L.-J., Xue, K., Yao, H.-Y., Quensen, J., Bai, S.-J., et al. (2015). Longterm balanced fertilization increases the soil microbial functional diversity in a phosphorus-limited paddy soil. Mol. Ecol. 24, 136-150. doi: 10.1111/mec.13010

Sul, W. J., Asuming-Brempong, S., Wang, Q., Tourlousse, D. M., Penton, C. R., Deng, Y., et al. (2013). Tropical agricultural land management influences on soil microbial communities through its effect on soil organic carbon. Soil Biol. Biochem. 65, 33-38. doi: 10.1016/j.soilbio.2013.05.007

Tao, R., Liang, Y., Wakelin, S. A., and Chu, G. (2015). Supplementing chemical fertilizer with an organic component increases soil biological function and quality. Appl. Soil Ecol. 96, 42-51. doi: 10.1016/j.apsoil.2015.07.009

Trivedi, P., Delgado-Baquerizo, M., Anderson, I. C., and Singh, B. K. (2016). Response of soil properties and microbial communities to agriculture: implications for primary productivity and soil health indicators. Front. Plant Sci. 7:990. doi: 10.3389/fpls.2016.00990

Wang, C., Liu, W., Li, Q., Ma, D., Lu, H., Feng, W., et al. (2014). Effects of different irrigation and nitrogen regimes on root growth and its correlation with aboveground plant parts in high-yielding wheat under field conditions. Field Crops Res. 165, 138-149. doi: 10.1016/j.fcr.2014.04.011

Wang, K. B., Zhang, Y. W., Tang, Z. S., Shangguan, Z. P., Chang, F., Jia, F. A., et al. (2019). Effects of grassland afforestation on structure and function of soil bacterial and fungal communities. Sci. Total Environ. 676, 396-406. doi: 10.1016/j.scitotenv.2019.04.259

Wardle, D. A. (2006). The influence of biotic interactions on soil biodiversity. Ecol. Lett. 9, 870-886. doi: 10.1111/j.1461-0248.2006.00931.x

Whitman, W., Goodfellow, M., Kämpfer, P., Busse, H.-J., Trujillo, M., Ludwig, W., et al. (2012). Bergey's Manual of Systematic Bacteriology, Volume 5: The Actinobacteria. New York: Springer-Verlag.

IUSS Working Group WRB (2007). "World reference base for soil resources 2006," in First update 2007. World Soil Resources Reports No. 103, eds E. Micheli, P. Schad, O. Spaargaren, H.-P. Blume, and R. Dudal, (Rome: FAO).

Wu, Q., Chen, F., Chen, Y., Yuan, L., Zhang, F., and Mi, G. (2011). Root growth in response to nitrogen supply in Chinese maize hybrids released between 1973 and 2009. Sci. China Life Sci. 54, 642-650. doi: 10.1007/s11427-011-4186- 6

Yao, H., Bowman, D., and Shi, W. (2006). Soil microbial community structure and diversity in a turfgrass chronosequence: land-use change versus turfgrass management. Appl. Soil Ecol. 34, 209-218. doi: 10.1016/j.apsoil.2006.01.009

You, M., Han, X., Chen, X., Yan, J., Li, N., Zou, W., et al. (2019). Effect of reduction of aggregate size on the priming effect in a Mollisol under different soil managements. Eur. J. Soil Sci. 70, 765-775. doi: 10.1111/ejss.12818

Yu, P., Liu, S., Han, K., Guan, S., and Zhou, D. (2017). Conversion of cropland to forage land and grassland increases soil labile carbon and enzyme activities in northeastern China. Agric. Ecosyst. Environ. 245, 83-91. doi: 10.1016/j.agee. 2017.05.013

Yuan, X., Nogi, Y., Tan, X., Zhang, R. G., and Lv, J. (2014). Arenimonas maotaiensis sp nova, isolated from fresh water. Int. J. Syst. Evol. Microbiol. 64, 3994-4000. doi: 10.1099/ijs.0.067769-0

Zhang, C., Liu, G., Xue, S., and Wang, G. (2016). Soil bacterial community dynamics reflect changes in plant community and soil properties during the secondary succession of abandoned farmland in the Loess Plateau. Soil Biol. Biochem. 97, 40-49. doi: 10.1016/j.soilbio.2016.02.013

Zhang, K., Cheng, X., Shu, X., Liu, Y., and Zhang, Q. (2018). Linking soil bacterial and fungal communities to vegetation succession following agricultural abandonment. Plant Soil 431, 19-36. doi: 10.1007/s11104-018-3743-1

Zhu, W., Lomsadze, A., and Borodovsky, M. (2010). Ab initio gene identification in metagenomic sequences. Nucleic Acids Res. 38:e132. doi: 10.1093/nar/gkq275

Conflict of Interest: The authors declare that the research was conducted in the absence of any commercial or financial relationships that could be construed as a potential conflict of interest.

Copyright (c) 2020 Zhang, Han, Yan, Zou, Wang, Lu and Chen. This is an open-access article distributed under the terms of the Creative Commons Attribution License (CC BY). The use, distribution or reproduction in other forums is permitted, provided the original author(s) and the copyright owner(s) are credited and that the original publication in this journal is cited, in accordance with accepted academic practice. No use, distribution or reproduction is permitted which does not comply with these terms. 